\title{
LAS BASES AFECTIVAS DEL POPULISMO
}

\section{THE AFFECTIVE FOUNDATIONS OF POPULISM}

\author{
Manuel Arias Maldonado \\ Universidad de Málaga \\ marias@uma.es
}

Recibido: Noviembre de 2017

Aceptado: Diciembre de 2017

Palabras clave: Populismo, emociones, afectos políticos, redes sociales, democracia, esfera pública.

Keywords: Populism, emotions, political affects, social networks, democracy, public sphere.

Resumen: Uno de los rasgos más destacados del populismo es su empleo de las emociones. Sin embargo, los análisis de la dimensión emocional del populismo suelen adolecer de cierta superficialidad. Este trabajo persigue, justamente, arrojar luz sobre las bases afectivas del populismo. A tal fin, presenta un análisis de los distintos aspectos de la afectividad populista, a partir de los hallazgos resultantes del giro afectivo experimentado por las ciencias sociales. Asimismo, se ocupa de los notables efectos que sobre la sentimentalidad populista tiene la reconfiguración digital del espacio público.

Abtract: One of the most prominent features of populism is its emotionality. Yet studies on the emotional dimension of populism tend to be rather superficial. Precisely, this article attempts to shed some light on the affective foundations of populism, taking advantage of the findings resulting from the affective turn that has taken place on the social sciences in the last years. In this connection, it also deals with the digital transformation of the public space and its effects on the populist sentimentality.

\section{l. Introducción}

No cabe duda de que el populismo se ha convertido en uno de los fenómenos políticos más prominentes de nuestro tiempo. De ahí que se hayan multiplicado los estudios académicos sobre el mismo, que en su mayor parte tratan de arrojar luz sobre la naturaleza y causas de un objeto que no se deja atrapar fácilmente. Y si hay algo que puede encontrarse en ellos casi invariablemente, sea como elemento nuclear o adjetivo, es la descripción del populismo como fenómeno emocional o que recurre habitualmente al emocionalismo. No habría populismo sin emociones, viene a sugerirse. Pero no es tan frecuente que se concrete el modo en que el populismo es emocional o se detallen sus estrategias afectivas. Más bien se da por supuesto que el recurso a un lenguaje recargado emocionalmente es eficaz, porque conecta con el estado de ánimo 
de los ciudadanos y proporciona a éstos una forma de canalizar sus sentimientos de indignación, miedo o resentimiento. Y aunque en buena parte así es, no está de más profundizar en la dimensión emocional del populismo, a fin de comprenderla debidamente. Es lo que se tratará de hacer este artículo.

Vaya por delante que el recurso a las emociones no es exclusivo del populismo, ni el populismo se agota en lo emocional. Por una parte, es razonable afirmar que todos los fenómenos políticos poseen una dimensión emocional y que no hay ideología política que no esté asociada a un sistema afectivo: si el socialismo otorga valor afectivo a la igualdad, el nacionalismo prefiere a la nación y el liberalismo la libertad. En las democracias de audiencia contemporáneas, marcadas por la construcción del candidato que se presenta a la mirada del público, el empleo de las emociones es parte sustancial de la estrategia comunicativa de cualquier partido político. Por otra parte, hay facetas distintas del populismo a las que prestar atención: desde el contenido de su discurso a sus estrategias de movilización, pasando por sus técnicas de reclutamiento o sus alianzas internacionales. Con todo, el uso de las emociones cumple una función indispensable en la ideología y la acción populista, por «delgada» que aquella -como veremos- pueda ser. De ahí que el populismo sea, junto al nacionalismo, la ideología contemporánea donde las emociones juegan un papel más destacado.

En cuanto a las emociones mismas, tampoco son precisamente una novedad. Pace Descartes, el ser humano es una criatura emocional y en modo alguno puede establecerse una contradicción insalvable entre racionalidad y afectividad. Si alguna conclusión firme puede deducirse del "giro afectivo" que se ha venido produciendo en los últimos años en las ciencias sociales -por influjo de las neurociencias y agotamiento del paradigma culturalista- es que razón y emoción se relacionan de manera tan compleja como ambigua (véase Arias Maldonado 2016). Esto no supone que haya de darse un cheque en blanco a la emocionalidad, pero sin duda deja claro que no podemos despacharla como mero irracionalismo. Máxime cuando, aunque los afectos no son nuevos, sí lo es nuestra mirada sobre ellos: el mencionado giro afectivo es el resultado natural de la crítica de un constructivismo radical que había dominado las ciencias sociales durante la segunda mitad del siglo XX bajo la premisa de que nada hay "dado" en el ser humano (véase Thompson y Hogget 2012). Ya no estamos tan seguros y la reinvindicación del papel que las emociones juegan en la determinación de nuestras decisiones y comportamientos así lo atestigua.

Finalmente, el estudio de la sentimentalidad populista debe incorporar otra novedad significativa, en este caso tecnológica. Se trata, claro, de la difusión de las nuevas tecnologías de la comunicación, que están modificando aceleradamente el espacio público democrático. De nuevo, hay que ser prudentes: el populismo existía antes de que lo hiciera Internet y resulta excesivo atribuir a las redes sociales toda la carga causal cuando queremos explicar hechos políticos en apariencia tan sorprendentes como las victorias del Brexit o Donald Trump. Descartar que hayan influido en ellos, empero, sería también precipitado: la habilidad con que el candidato Trump logró sortear a los medios tradicionales que se le oponían unánimemente, comunicándose directamente por Twitter con sus seguidores, contribuyó 
notablemente a su popularidad. Parece claro que las redes sociales han proporcionado a los movimientos y líderes populistas una herramienta que encaja muy bien con el sentido de su mensaje central -el poder debe ser devuelto al pueblo- y que, de hecho, facilita la operación performativa mediante la cual se invoca o incluso se constituye ese mismo pueblo.

El trabajo se estructurará como sigue. En primer lugar, se caracterizará brevemente el populismo, a fin de demarcar la noción que del mismo aquí se maneja, y se dará especial énfasis a su conceptualización como "estilo político". A continuación, se abordará en detalle la afectividad populista, vale decir, se identificarán cuidadosamente aquellas facetas del populismo que pueden caracterizarse como emocionales o recurren al empleo de las emociones. Finalmente, se considerarán aquellas novedades que, para la sentimentalización de la democracia y en especial para la explotación populista de la sentimentalidad, comporta la generalización de las nuevas tecnologías de la comunicación. Una breve conclusión cerrará el texto.

\section{El populismo como estilo político}

"Power to the people!": pocas exclamaciones tienen más resonancia emocional dentro de la vida política. La hemos visto en pancartas, libros, canciones; se ha empleado para promover revoluciones democráticas y como eslógan para campañas electorales. Se trata de una fórmula que, en nombre de la verdadera democracia, reclama el poder para un pueblo llamado a gobernarse directamente en lugar de ser gobernado por unos pocos. Y ésa es, en esencia, la demanda del populismo.
De ahí proviene su capacidad disruptiva, que podrá manifestarse cada vez que una comunidad humana encuentre motivos para rebelarse contra una injusticia o lo que se percibe como una injusticia. Pero es conveniente distinguir entre sus raíces psicopolíticas, manifestadas allá donde encontremos una rebelión popular contra las élites, y sus manifestaciones modernas, donde la democracia auténtica (o directa) es invocada contra la democracia inauténtica (o representativa). Por eso podemos decir que el populismo es un fenómeno intrínsecamente democrático.

Dicho esto, el populismo ha tenido una accidentada vida académica. La diversidad de los movimientos a los que se aplica el término, sumada a la naturaleza camaleónica de un credo abrazado por igual a izquierda y derecha del espectro ideológico, ha provocado dudas acerca de su verosimilitud. Se ha llegado a afirmar que no existe el populismo, sino solo el conjunto abigarrado de sus manifestaciones (Werz 2003: 13). El populismo es así un concepto esencialmente discutido y conceptualmente inasible (Taggart 2000: 1). Sin embargo, es necesario rehuir el derrotismo conceptual. El populismo no es el primer concepto discutible al que se enfrenta la ciencia social, ni es una novedad que la propia discusión sobre su campo semántico posea connotaciones políticas. Matices al margen, los estudiosos se refieren a un mismo fenómeno cuando hablan de populismo; este es, pues, definible e identificable. Aunque, por supuesto, la realidad siempre será más heterogénea que sus representaciones conceptuales (véase Rivero et al. 2017). No siendo objeto específico de este trabajo realizar un detallado análisis conceptual del populismo, me limitaré a continuación a trazar una distinción entre sus elementos 
nucleares y adjetivos, así como a discutir brevemente el problema de su forma.

Cuando hablamos de populismo, puede establecerse una distinción entre elementos nucleares y adjetivos: si los primeros constituyen el núcleo esencial sin el cual no podemos hablar de populismo, los segundos suelen acompañarlo pero no alcanzan para definirlo, entre otras cosas porque pueden estar presentes en otros movimientos políticos. Tal vez podamos hablar también de elementos ideacionales y elementos estilísticos: los primeros componen la sustancia del populismo y los segundos sus atributos formales. De esta forma, recurriendo a un núcleo básico que debe concurrir para que hablemos de populismo, resolvemos la confusión analítica que causa el presentar como constitutivos del mismo algunos rasgos que no siempre lo acompañan.

Nucleares son, así, cuatro elementos que se presentan interrelacionados. A saber: la postulación de dos unidades homogéneas de análisis: el pueblo y la élite; la existencia de una relación de antagonismo entre ambas; la valoración positiva del "pueblo" y la denigración de la "élite"; la idea de la soberanía popular, traducida en la primacía de la voluntad general como matriz decisoria (Stanley 2008: 102). Es aquí decisivo el contraste moral entre una élite parasitaria y un pueblo virtuoso. En principio, ese pueblo se presenta como un bloque homogéneo e indivisible, si bien el pueblo "auténtico" es solo una parte del pueblo "ordinario". De hecho, el populismo no dice "nosotros también somos el pueblo", con objeto de incluir a minorías (o mayorías) presuntamente excluidas, ni tampoco "nosotros somos el pueblo", sino "sólo nosotros somos el pueblo» (Müller 2016: 44). Que el populismo sea antipluralista no puede constituir, entonces, ninguna sorpresa.
A este núcleo pueden añadirse otros rasgos, que no son exclusivos del populismo pero se encuentran presentes -de manera variable- en la mayoría de sus manifestaciones. Entre ellos se incluyen la organización alrededor de un líder carismático, el anti-intelectualismo, el empleo de un registro comunicativo emocional, la identificación con una patria idealizada, así como un repertorio de acción basado en la provocación, la polarización y la protesta. Aunque sería difícil encontrar un movimiento populista que no participe de algunos de estos ragos, parece razonable afirmar que son facilitadores antes que definitorios del populismo (Van Kessel, 2015). Así como el antagonismo moralizante pueblo/élite es inherente al populismo, por ejemplo, los partidos populistas no son los únicos liderados por personalidades carismáticas: sin lo primero no hay populismo, sin lo segundo puede haberlo.

Ahora bien, aunque podamos estar razonablemente de acuerdo en lo que sea el populismo, no acabamos de ponernos de acuerdo acerca de la forma en que se manifiesta. Se trata de un problema clásico en los estudios sobre el tema, donde la palabra ha terminado por abarcar realidades tan distintas que, tan pronto como en los estudios seminales de la década de los 60, ya no estaba claro si había de primar la dimensión ideológica (las ideas del populismo) o la organizativa (sus distintas manifestaciones) [veánse lonescu y Gellner, 1969]. Me limitaré a señalar aquí, brevemente, cuatro posibilidades.

a) El populismo como ideología. Es decir, una que ve la sociedad separada en dos grupos homogéneos -la gente y la élite, o la gente y "los otros" que privan a aquella de su prosperidad, identidad, voz- y defiende que la política debería ser la expresión de la "volun- 
tad general" en sentido rousseaniano (Mudde, 2004: 543; Albertazzi y McDonnell, 2008: 3). En este sentido, estaríamos hablando de una ideología "delgada" o débil, que no posee respuestas propias para todos los problemas de la vida social (véase Freeden, 1998). Por esa razón, podría cohabitar con ideologías más comprensivas; puede así ser tanto de izquierda como de derecha.

b) El populismo como estrategia. El populismo puede verse también como una estrategia política empleada para ganar o retener apoyo social. Mediante un liderazgo carismático, el populismo busca el gobierno o lo ejerce sobre la base de un apoyo directo y no institucionalizado de sus desorganizados seguidores (Weyland, 2001: 14). A la cualidad camaleónica antes sugerida podríamos entonces darle la vuelta: un partido o movimiento que profese una ideología "gruesa" o clásica puede adoptar el disfraz populista para acceder al poder. Está, como cualquier otra estrategia, a disposición de cualquier actor político.

c) El populismo como discurso. Desde este punto de vista, el populismo no sería un conjunto de creencias políticas, sino un modo particular de expresión política, que se hace visible en el habla y el texto, enfrentando al pueblo contra la élite (De la Torre 2010). A diferencia de los enfoques ideológico y estratégico, éste permite entender el populismo como una propiedad susceptible de medición: más que ser o no populista, es posible serlo en distinta medida y en distintos momentos. Será entonces populista quien despliegue un discurso populista; algo que puede discernirse, en el plano metodológico, mediante el análisis de discurso. (c) El populismo como estilo político. Otra posibilidad es concebir el populismo como una forma comunicativa mediante la cual los actores políticos se dirigen a los ciudadanos. En principio, cualquier actor que emplease este "estilo", podría estar haciendo populismo. Pero no es un estilo cualquiera. Moffit y Tormey (2014) sostienen que el populismo es un estilo por sus marcadas cualidades performativas y estéticas. O sea: los líderes, a través del discurso y demás herramientas expresivas a su disposición, modifican o crean la subjetividad del público y, con ello, dan forma al pueblo. Hemos de contemplar el populismo, entonces, en el marco del declive de los clivajes tradicionales y la creciente "estilización" de la política, que va de la mano de la simplificación del discurso político y la formulación de antagonismos irreconciliables. Huelga decir que la creciente medialización de la sociedad contribuye de manera notable a esta transformación.

Desde luego, no es fácil determinar cuál de estas concepciones del populismo nos dice la verdad sobre un fenómeno tan rico en manifestaciones empíricas como denso en significados teóricos. Sin embargo, nada nos obliga a elegir uno de estos enfoques. Hay quien ha descrito el populismo como un discurso y una estrategia política (De la Torre 2010: 7); también se ha apuntado que puede operar de varias formas, por ejemplo como ideología y estrategia (Van Kessel 2015). En fin, nada obsta para que reconozcamos en el populismo una ideología delgada o débil que, mediante un estilo político performativo que contiene elementos discursivos y no discursivos, opera de facto como una estrategia de movilización política para la conquista del poder. Con todo, este trabajo enfatizará la caracterización del 
populismo como estilo político, que es coherente con sus manifestaciones más contemporáneas y presta la debida atención a los aspectos no discursivos -pero desde luego lingüísticos o semióticos- del desempeño de los actores populistas: no solo a lo que dicen, pues, sino a cómo lo dicen y a los efectos que ello produce sobre su audiencia.

\section{La afectividad populista}

El populismo es un fenómeno afectivo. Ya lo dijo Juan Domingo Perón, líder del peronismo argentino y uno de los más exitosos líderes populistas de la historia política occidental: "El populismo es una cuestión de corazón más que de cabeza". Es ahora, no obstante, cuando podemos estudiar con mayor precisión el núcleo emocional del populismo gracias a los avances registrados en el estudio de los afectos humanos y sus implicaciones políticas.

Ya se ha dicho que el populismo está lejos de ser el único movimiento político que emplea medios emocionales para buscar apoyo, movilizar a sus seguidores o tratar de realizar sus fines. En principio, lo que se diga de las emociones populistas puede predicarse también de las emociones socialistas o liberales o conservadoras: todas las ideologías o doctrinas despliegan un régimen afectivo particular y movilizan emociones concretas, invistiendo a determinados conceptos o significados -igualdad, libertad, tradición, feminidad, naturaleza- de cualidades afectivas. Si algo ha puesto de manifiesto el reciente giro afectivo en las ciencias sociales, es que las emociones juegan un papel mucho mayor de lo previsto en el modo en que los individuos perciben los asuntos públicos, los evalúan y toman decisiones políticas (véase Forgas 2000). La afectividad no puede ser exclusiva del populismo ni de los populistas. Sin embargo, hay razones para pensar que el populismo es especialmente propenso al empleo de las emociones, que por tanto juegan un papel prominente en sus fundamentos doctrinales y su despliegue performativo. Trataremos de mostrarlo a continuación, describiendo los principales elementos de la afectividad populista.

3.1. En primer lugar, el populismo rechaza el racionalismo como fundamento del orden social. O sea, cuestiona frontalmente la idea, de raigambre ilustrada, de que las democracias sean construcciones racionales o puedan fundarse sobre una base racional (Villacañas 2015: 15-16). El vínculo social sería, por el contrario, de índole sentimental: se basaría en la comunión emocional del pueblo con el líder y en el rechazo visceral de sus enemigos. Donde hay pluralismo, no hay unidad; donde hay división, no hay pueblo. Por eso, el populismo aspira a construir lazos afectivos entre los individuos al margen de sus diferencias socioeconómicas. Podríamos así decir que el pueblo es una ilusión en un doble sentido: como activador de emociones positivas y como espejismo de unidad. El populismo cree resolver así el problema que deja en el aire el liberalismo, que es definir y dar existencia al pueblo. Se explica también por este camino la preponderancia de la multitud frente al ciudadano en el universo populista: del cuerpo colectivo que opera como unidad frente a la pluralidad de individuos y cuya subsunción en un todo sólo puede ser coyuntural.

3.2. Para lograr ese objetivo, el populismo trabaja con los sentimientos negativos experimentados por los distintos grupos sociales, a menudo provocados por una 
situación de crisis, con objeto de convertirlos en sentimientos positivos que no obstante retienen su ambigüedad. Esto quiere decir que esos sentimientos son identificados y nombrados, pero también fomentados y potenciados. De distintas maneras: denunciando injusticias, señalando a los presuntos culpables, estimulando su condena. A menudo, se recurre para ello a la exageración y la simplificación, eliminándose cualquier atisbo de responsabilidad -electoral, por ejemplopor parte de aquellos que forman parte del pueblo agraviado por el establishment. Sentimientos negativos son aquí la indignación, el resentimiento o el miedo; positivos serían la esperanza de que las cosas puedan cambiar y la ilusión en el movimiento político que, denunciando al status quo, promete derribarlo. Nótese, asimismo, que la identificación con el cuerpo colectivo del pueblo es también ambivalente y puede describirse como constitutiva de una pertenencia agresiva: la satisfacción emocional y psicológica que proporciona sentirse parte de una comunidad coexiste con el rechazo visceral de los enemigos de la misma.

3.3 El papel de las emociones se manifiesta igualmente en la preferencia del populismo por una democracia de corte agonista, o sea, organizada alrededor de las pasiones políticas de los ciudadanos. Frente a la preferencia liberal por el consenso, el agonismo denuncia la naturaleza adormecedora de éste, que puede funcionar como mecanismo encubridor de injusticias y ahogar las voces de los más desfavorecidos. Se defiende, en cambio, que la finalidad de la democracia es canalizar un conflicto -entre amigos y enemigos- que conforma la esencia de la política. Inspirada por esa distinción amigo/enemigo, Chantal Mouffe (2000) caracteriza la política agonista como el esfuerzo por fomentar relaciones entre "enemigos amigables": ciudadanos que comparten el espacio simbólico común de la democracia, pero discrepan sobre cómo habría de organizarse ese espacio. Es en este marco donde Mouffe defiende la necesidad de introducir las pasiones humanas, entendidas como motivaciones para la acción política y como signos de identificación colectiva. La democracia agonista, cuya traducción institucional esta aún pendiente, se convierte así en el modelo político más apropiado para la acción populista, al estimular el enfrentamiento apasionado entre cosmovisiones e identidades rivales y descreer del consenso liberal. Aunque quizá sería más exacto afirmar que es la acción populista la que convierte la democracia liberal en democracia agonista, mediante el despliegue de un estilo político basado en el antagonismo y la emocionalidad.

3.4 Asimismo, la construcción del antagonismo entre pueblo y élite se apoya sobre un conjunto de mecanismos psicológicos y afectivos que remiten a los déficits de racionalidad del sujeto politico. Pueblo contra élite, no importa cómo se defina en cada caso el contenido de cada una de esas dos entidades enfrentadas: si recurrimos a los teóricos contemporáneos de los sentimientos morales, que se aproximan al estudio de estos últimos con las herramientas de la teoría evolucionista, nos encontramos con que el antagonismo en cuestión posee un fundamento biológico y, por tanto, eminentemente afectivo. Para Greene (2013), se trata de una respuesta evolutiva: los mismos mecanismos que han facilitado la cooperación social intragrupal dificultan la cooperación con miembros de otro grupo, reforzándose así la sepa- 
ración de los seres humanos en distintas tribus morales adscritas a cosmovisiones y valores morales dispares. Parafraseando a Daniel Kahneman (2011), podríamos distinguir entre una moralidad lenta y una moralidad rápida: si la primera es cognitiva y flexible, la segunda es intuitiva y eficiente. Cuando nos adherimos a nuestro grupo -como sucede con el pueblo del populista- hacemos uso de una moralidad rápida. Los instintos tribales no solo facilitan la cooperación intragrupal, sino que condicionan de partida nuestra percepción de los argumentos y valores que puedan estar en juego, pues automáticamente sobrestimamos unos pero subestimamos otros (Haidt, 2012). Kahneman (2003) ha hablado de una "saturación afectiva", para describir el fenómeno por el cual nuestras emociones tiñen nuestras percepción, condicionando sin que nos apercibamos de ello nuestra evaluación cognitiva de una situación, tema o figura política. Se deduce de aquí que, cuando del antagonismo entre grupos se trata, el contenido particular de las creencias es menos importante que los sentimientos que experimentamos; son los sentimientos los que nos hacen compartir las creencias. Por último, hay que tener presente que los movimientos políticos asociados a la idea de pertenencia, ya sea nacional o popular, se correlacionan a menudo con una etnicidad que se alimenta de las emociones arcaicas vinculadas a la vida comunitaria (Gat y Yakobson, 2013). Desde este punto de vista, la pertenencia sería una necesidad emocional de raíz evolutiva y no una expresión de conservadurismo (Baumeister y Leary, 1995). En fin, de esos mecanismos de identificación se sirve el populismo cuando promueve eso que más arriba hemos llamado pertenencia agresiva al pueblo; pueblo cuya representación simbólica y política él mismo se arroga. No sería descabellado afirmar que el populismo es aquel estilo político cuyo presupuesto operativo es el tribalismo moral.

3.5. Por lo demás, otro aspecto de la afectividad política de la que se sirve -aunque no en exclusiva- el populismo es la propensión del individuo a estructurar su comprensión de los asuntos públicos por medio de relatos o historias. Las narraciones hacen posible que nos vinculemos emocionalmente con los acontecimientos, pues son esas estructuras narrativas las que ordenan nuestra percepción de la realidad (Westen, 2007; Hamman y Pilecki, 2012). Todos los actores políticos tratan por ello de fabricar historias que tratan de representar narrativamente una idea, valor o sentimiento, a fin de que sus receptores la interioricen más fácilmente. Tanto el llamado storytelling como el framing o enmarcamiento (que presenta bajo una luz determinada, mediante distintas técnicas narrativas o semánticas, los asuntos que forman parte de la agenda pública) persiguen esa finalidad (véase Lakoff, 2004). En el caso del populismo, el relato es sencillo pero poderoso: el pueblo, sojuzgado injustamente por las élites, ha de recuperar el poder a fin de reparar las injusticias de que ha sido objeto. Si pensamos en la reciente crisis financiera, su enmarcamiento como engaño deliberado de unas élites deseosas de enriquecerse a costa de los ciudadanos corrientes ofrece el perfecto pie para el relato populista, asociado a su vez a sentimientos de indignación y malestar.

3.6. Hay que tener en cuenta, no obstante, que el contenido del "pueblo" del populismo no se encuentra prefijado en ninguna parte; lo mismo que sucede con el pueblo del nacionalismo. Koselleck tiene explicado que la definición del pueblo 
depende de dos ejes: uno que va de abajo a arriba en el interior de la comunidad política y otro que distingue entre quienes están dentro y quienes se quedan fuera de él (Koselleck 1978: 145). Pero la operación mediante la que se precisa ese contenido pertenece necesariamente al orden afectivo. Así lo razona Ernesto Laclau (2005), teórico del populismo para quien términos como "pueblo" o "élite" son "significantes vacíos" esperando a ser rellenados de un modo u otro en función de la estrategia movilizadora del movimiento en cuestión o la cultura política dominante. Para Laclau, no existe ningún significado que no esté sobredeterminado emocionalmente. Y el pueblo se construye por medio de una operación de orden emocional por la que "investimos" a ese concepto con valores positivos .

3.7. El líder juega un papel esencial en la estrategia afectiva populista, pues encarna y personifica la abstracción en que consiste el pueblo en cuyo nombre actúa ese mismo líder. En las certeras palabras de José Luis Villacañas (2015: 16): "La función del líder es transformar representaciones conceptuales siempre defectivas en representaciones afectivas". Hugo Chávez lo expresó inmejorablemente: "Yo no soy un individuo. Yo soy el pueblo". Se hace así posible una identificación, del seguidor con el líder y por tanto con el movimiento, que es emocional antes que racional. Entre otras cosas, porque opera en el terreno inmediato de las percepciones; de ahí la importancia que, como veremos más abajo, tiene la dramatización que de sí mismo hace el líder populista. O sea, la construcción de su imagen como agente del malestar ciudadano y representante que no necesita de mediaciones por relacionarse directamente con el pueblo.
3.8. Finalmente, hay que tener en cuenta que el estilo político populista posee una dimensión performativa que contiene importantes elementos afectivos. No puede ser de otra manera, si tenemos presente que la estrategia populista pasa por la dramatización de una crisis y la escenificación del subsiguiente conflicto entre pueblo y élite. Para ello, es frecuente la deslegitimación de la democracia representativa ("no nos representan") y la legitimación de las formas directas o aclamativas de democracia. En ese sentido, el lenguaje simplista y políticamente incorrecto que suelen emplear los líderes populistas debe entenderse como expresión del antagonismo pueblo/élite. Canovan (1981) lo ha descrito como un "estilo tabloide", mientras Moffit (2016: 55) prefiere hablar de "malos modales": en ambos casos, el líder populista trata de encontrar un equilibrio performativo entre la apariencia extraordinaria (liderazgo redentor) y la ordinaria (identificación popular). Su lenguaje desacostumbrado, incorrecto, posee una cualidad catártica a ojos de quienes identifican la expresión política estándar con las fórmulas de compromiso y la voluntad deliberada de ocultar temas sensibles como la inmigración o la desigualdad bajo el pretexto de que las cosas no pueden hacerse de otro modo. Nótese que el líder populista debe presentarse ante sus seguidores como un outsider, esto es, alguien que no pertenece al sistema político que ha secuestrado la democracia y perjudicado los intereses del pueblo; solo así, además, será creíble su promesa de regenerarlo. Esta forma de presentarse ante el ojo público suministra al movimiento populista -que no por casualidad se presenta a sí mismo como entidad siempre en marcha- un poderoso relato de confrontación con el establish- 
ment. Para diferenciarse del sistema, el líder populista recurrirá así a distintas estrategias auto-representativas: podrá vestir el atuendo de las minorías indígenas (Evo Morales), despreciar el traje y demás atributos de formalidad indumentaria (Pablo Iglesias) o describirse como un hombre de negocios ajeno a la política capitalina (Donald Trump). Se hace así evidente que la relación con los ciudadanos no se establece únicamente a través del discurso, sino mediante una performance global que incluye ideas, vocabulario, acentos, lenguaje corporal, gestos, atuendos. Esto no implica necesariamente vulgaridad, pero sí diferencia respecto de los demás políticos; el líder populista encarna la novedad disruptiva que acaba con una inercia perjudicial para los ciudadanos. Es patente la importancia que el nivel estético tiene en el despliegue populista, que posee un "estilo político" (Pels 2003) reconocible. Todos estos elementos performativos, por tanto, sirven para construir la imagen de un líder capaz de expresar, por medios verbales y estéticos, aquello que el populismo quiere representar: el movimiento de rechazo del establishment en nombre del pueblo.

La importancia de la performatividad en la movilización de los sentimientos de pertenencia al "pueblo" enunciado por el líder exige atender a los instrumentos que, en cada momento histórico, conforman el repertorio de acción del populismo. Hablamos, ante todo, de aquellas herramientas que permiten la comunicación con el público y la autorrepresentación del líder o movimiento. Huelga decir que el populismo no disfruta de este repertorio expresivo en régimen de monopolio, sino que todos los partidos políticos y movimientos sociales los tienen a su disposición. Por otra parte, se trata de un repertorio acumulativo, pues los nuevos medios de comunicación y construcción de la imagen rara vez desplazan por completo a los precedentes. Si bien la medialización de la sociedad contemporánea recibe un impulso decisivo con el desarrollo de los medios digitales y la difusión del smartphone, hasta el punto de que se ha afirmado con razón que ya no vivimos con los medios sino en los medios (Deuze, 2012), es asimismo cierto que la televisión y la radio siguen exhibiendo un notable vigor y que hay formas tradicionales -casi primitivas- de comunicación política que no han perdido un ápice de su utilidad: desde el mítin a la manifestación. Con todo, la digitalización de la esfera pública es un fenómeno sustantivo que está provocando, a velocidad de vértigo, una reconfiguración del espacio público democrático (véase Arias Maldonado, 2017). Y como quiera que el tipo de comunicación que fomentan las redes digitales posee fuertes acentos emocionales, no parece que podamos estudiar el populismo sin preguntarnos por el papel que juegan aquellas.

\section{Sentimentalidad populista y digitalización del espacio público}

Es conveniente, antes de explorar la relación entre la afectividad populista y la digitalización de la esfera pública, formular una advertencia: el populismo no es una consecuencia de la comunicación digital. ¿Estamos seguros de que Trump ha ganado por disponer de una cuenta en Twitter, el abismo generacional expresado en el Brexit no existiría sin Facebook, o los hechos eran más decisivos que las emociones en las democracias de antaño? En última instancia, la agitación po- 
lítica contemporánea puede explicarse como reacción psicopolítica a los sucesos que, desde el atentado yihadista del 11-S a la Gran Recesión, han resquebrajado el suelo firme de las sociedades liberales que habían emergido triunfantes tras el colapso soviético (véase Lassalle, 2017). También se ha dicho que la emergencia del populismo responde a una crisis de la democracia liberal, cuyo funcionamiento dependería en cada vez mayor medida de imperativos sistémicos y normas "racionales" aparentemente invulnerables ante los que la emotividad populista se rebela poniendo en cuestión una supuesta "normalidad" (Vallespín y MartínezBascuñán, 2017: 82). Sea como fuere, es igualmente desaconsejable juzgar como simple coincidencia el ascenso en paralelo de populismo y redes digitales, sobre todo teniendo en cuenta el empleo que el primero hace de las segundas. Más plausible resulta, prima facie, contemplar las redes digitales como facilitadoras del populismo. Y ello, como veremos enseguida, debido a su peculiar naturaleza.

Las redes sociales que canalizan la mayor parte de la actual conversación pública, ¿hacen que la comunicación sea más emocional? ¿O, por el contrario, refuerzan sus componentes racionales y por tanto sus funciones deliberativas? ¿Y de qué modo se relacionan con el populismo? Estas preguntas, valga la cautela, han de responderse sin incurrir en la falacia retrospectiva que idealiza el empleo de la razón pública en el pasado: nunca ha existido, ni existirá jamás, una democracia plenamente racional. Pero, obviamente, hay grados de racionalidad.

Ahora mismo, se hace difícil sostener la afirmación de que la digitalización de la esfera pública ha contribuido a mejorar la calidad del debate público. Fenóme- nos como la posverdad y las fake news ponen de manifiesto que la disrupción de los medios tradicionales produce efectos negativos sobre el funcionamiento de la democracia; al menos, por el momento. Las razones son ya conocidas: las redes sociales son menos las fuentes de nuestra información que la estructura de la nueva conversación pública. Ahora los ciudadanos son co-protagonistas en la creación de opinión: la comunicación vertical de masas se complementa con la autocomunicación horizontal de masas, cuyos integrantes crean y distribuyen contenidos propios (véase Castells, 2009). A ello hay que sumar el comentario y difusión de los contenidos creados por los medios tradicionales, con los que las redes mantienen una relación parasitaria. Pues bien, si algo vamos sabiendo de las redes sociales y demás instrumentos de comunicación digital, como los blogs o la sección de comentarios en las páginas web de periódicos o revistas, es que facilitan la exposición selectiva a las noticias y puntos de vista que encajan con los nuestros, reduciendo con ello la diversidad de opiniones a las que nos vemos expuestos y estimulando nuestros instintos más tribales. A ello contribuye el hecho de que la hiperconectividad contemporánea ha multiplicado el número de ciudadanos que se relacionan, por fuerza superficialmente, con la vida política: la conversación tiene más participantes, pero estos son menos deliberativos.

Se ha señalado así que el empleo de estos nuevos instrumentos comunicativos se produce a expensas del "racionalismo retórico" que había dominado los medios escritos tradicionales: ahora prevalecería un lenguaje más "auténtico" que privilegia el registro emocional, la experiencia personal y la actitud de sospecha hacia 
las élites (véase Thompson 2016). Es, por tanto, un registro que encaja como un guante en la disposición populista. Más que fomentar una deliberación racional e informada, las redes sociales modulan y amplifican un estado de ánimo; operan por contagio y de ahí el éxito de las metáforas virales. Este debilitamiento de la argumentación racional implica que la persuasión afectiva pasa a ser dominante. Sin embargo, no estamos tampoco ante un ejercicio de persuasión, sino ante respuestas de carácter automático: reaccionaríamos favorablemente a aquellos contenidos que identificamos como alineados con nuestra tribu moral, compartiéndolos o destacándolos, rechazando en cambio los que percibimos como provenientes de las tribus rivales o desalineados con nuestras emociones y creencias.

Los votantes se convierten así en receptores -aunque también transmisores y retransmisores- de mensajes engañosamente simples que contienen términos (o acepciones de términos) investidos de sentido simbólico y valencia emocional. Pensemos en la "democracia" del independentismo catalán, en la "soberanía" de los partidarios del Brexit, en la "Francia" de Marine Le Pen. Es cierto que, como ha defendido Russell Neuman (2016), no hay acto de comunicación que no esté "valenciado": no hay transmisión inocente. Pero es novedoso el hecho de que las tecnologías digitales y las redes sociales permitan crear en los votantes la impresión de que el emisor se dirige directamente a ellos. Se trata de una comunicación no mediada que, como demuestran los casos de Donald Trump y Pablo Iglesias, crea un vínculo emocional entre líderes y seguidores, al tiempo que permite al primero proveer de argumentos y directrices a los segundos. $Y$ es que las redes hacen más fácil que los movimientos populistas provean a sus seguidores de noticias de producción propia, reforzando la desconfianza hacia los medios de comunicación mainstream y los políticos convencionales fomentada por el discurso anti-establishment del populismo. Aunque no es una novedad absoluta: el Partido Comunista francés mantuvo durante décadas un periódico, L'Humanité, que llegó a tener 500.000 lectores en la segunda posguerra mundial. Sí que hay, en cambio, diferencias de escala: en ese mismo país y en el momento de escribir estas líneas, Marine Le Pen tiene cerca de dos millones de seguidores en Twitter.

El público se encuentra, a su vez, más fragmentado que en el pasado. La profusión informativa, que se traduce en una lucha descarnada entre los medios por llamar la atención de los usuarios y se reproduce también entre éstos, refuerza los aspectos emocionales de la comunicación digital. Por una parte, los emisores recurren a mensajes cada vez más hiperbólicos o sensacionalistas, con objeto de atraer al mayor número posible de receptores. Algo que, otra vez, no es ajeno a un estilo populista que recurre habitualmente a la provocación y la protesta como tácticas discursivas. Simultáneamente, el público se está fragmentando, en lo que supone la culminación de un proceso que comenzó con la difusión de la televisión por cable (véase Wu, 2012). A fin de cuentas, no hay una sola red social, sino que dentro de cada una de ellas elegimos a nuestros interlocutores y conformamos nuestro propio universo informativo. Por eso se ha dicho que las redes constituyen "cámaras de resonancia" donde sólo escuchamos el eco de nuestra propia voz; un "efecto silo" que separa a los ciudadanos en grupos que no se comunican entre 
sí salvo para pelearse. Esta cualidad también puede predicarse de la blogosfera, un espacio compartimentalizado que refuerza las disposiciones previas del público en lugar de desafiarlas. En su interior, pues, nos aislamos junto con las personas que piensan lo mismo que nosotros y comparten contenidos que, por coincidir con nuestras creencias, nos hacen sentir bien (véanse Sunstein 2008, Reese et al. 2007). Se trata de un bienestar, conviene apuntarlo, neurobiológico: nos sentimos mejor físicamente cuando leemos algo que coincide con nuestras opiniones (véase Kolbert, 2017).

En estas circunstancias, es inevitable que se produzca un aumento de la polarización en el debate público, reflejo al cabo de la propensión humana al antagonismo intergrupal y el malentendido comunicativo. Proporcionando a cada individuo una plataforma desde la que emitir opiniones en contacto con otras opiniones, las redes sociales refuerzan el narcisismo del sujeto que convierte su posición en un fetiche con alto valor psicológico. Nuestras opiniones son entonces un medio para el reforzamiento de nuestra subjetividad y de ahí que nos aferremos a ellas en lugar de abrirlas a la argumentación pública (Vallespín 2012: 108). Se ha propuesto la imagen de una "democracia de enjambre» para describir la interacción comunicativa resultante, protagonizada por muchedumbres reactivas que llenan de ruido el espacio común y operan en la práctica como públicos afectivos (Han, 2013). Para explicar este fenómeno, hay que tener en cuenta que la política se ha convertido en una rama del entretenimiento ciudadano: pasar tiempo en las redes compartiendo contenidos que nos hacen sentir mejor y discutiendo acaloradamente con quienes pertenecen a otras tribus morales puede ser divertido e incluso adictivo. En esta línea, se ha hablado de la creación de un vínculo afectivo de orden identitario entre líderes y seguidores, que refuerza el carácter plebiscitario de la política contemporánea; su manifestación más clara, justamente, se encuentra en las distintas inflexiones del populismo. Emerge así un "fan político" que confirma la nueva cualidad de la política como entretenimiento de masas (véase Sandvoss, 2013).

Todo lo anterior está en la raíz del fenómeno de la democracia post-factual, que puede entenderse a la vez como causa y consecuencia del populismo. Por una parte, éste socava la confianza en los expertos y el debate racional; por otro, su descrédito facilita el crecimiento del populismo. Los hechos no serán percibidos y juzgados de acuerdo con su verosimilitud o con la credibilidad de la fuente que los comunica, sino en función de si los sentimos verdaderos o falsos. La verdad será, pues, una función de las creencias. Por supuesto, la mentira es una vieja compañera de viaje de la política, pero la posverdad (con arreglo a la cual no habría verdad sino verdades condicionadas por el punto de vista desde el que se las formulan) y el posfactualismo (o pérdida del valor persuasivo de los hechos) no pueden entenderse sin el concurso de la tecnología y la afectividad. Sunstein (2009) ha demostrado cómo la conexión digital de individuos con creencias políticas similares multiplica la velocidad de circulación de los rumores y las teorías conspirativas, que se presentan como "auténtica realidad" de las cosas frente a la verdad oficial defendida por el establishment. Pero si los hechos pierden valor persuasivo, la performance política cobra incluso mayor importancia. El estilo populista se ve así favorecido por la digitalización y explica 
que algunos actores políticos no populistas tomen elementos del mismo para presentarse eficazmente ante el electorado.

Otro aspecto de la digitalización que se relaciona con la afectividad populista es la creación de un nuevo tipo de público, más organizado alrededor de sentimientos que de razones o intereses. Recordemos que Internet rebaja dramáticamente los costes de cooperación y, por tanto, abarata extraordinariamente la creación de comunidades y públicos (Howard and Hussain 2013). Se ha sugerido al respecto que la actividad online no crea tanto comunidades en sentido propio como "sentimientos comunitarios" o "el sentimiento de contar" (Coleman 2013). Es una vida conectiva más que colectiva; $\mathrm{o}$, si se prefiere, una conectividad emocionalmente recargada. A fin de cuentas, la comunicación digital en red "implica la circulación de datos e información, así como toda una panoplia de vínculos afectivos" (Paasonen, Hillis and Petit, 2015: 1). Y si las estructuras digitales reticulares que nos permiten expresarnos y conectarnos se caracterizan por su sentimentalidad, darán lugar a "públicos afectivos": formaciones en red cuya movilización tiene lugar a través de expresiones sentimentales (Papacharissi 2016). Al mismo tiempo, la participación individual en las redes sociales implica por parte del usuario un cierto grado de performatividad: en las redes sociales hacemos algo, al tiempo que adornamos ese hacer por sabernos observados (Schechner 2002). Aunque esto no es negativo en sí mismo, dista de responder a las prescripciones normativas de los modelos clásicos de la opinión pública. El enfoque clásico se basa en la premisa de que las democracias son racionales, cuando en realidad son más bien ruidosas y cacofónicas (Panagia 2009: 48).
Es pronto para saber si estos cambios en el tejido de las democracias liberales, en apariencia sustanciales, son también duraderos. Hasta el momento, en cualquier caso, la tecnología parece estar jugando en favor del estilo político populista y los sentimientos que trata de despertar. Además de las razones ya expuestas, hay que hacer notar cómo la novedad que constituye la comunicación no mediada produce una sensación de "empoderamiento" en los ciudadanos. De esto se beneficia el populismo, ya que este último no solamente fomenta el antagonismo entre pueblo y élite, sino que subraya el principio según el cual la democracia es el gobierno del pueblo, por el pueblo y para el pueblo. Tal es, de hecho, la ideología de la democracia. O sea, el credo que legitima el sistema a ojos de los ciudadanos, a pesar de que en la práctica la democracia solo pueda existir -al menos en sociedades complejas de cierta escala- como una combinación de elemenos liberales y democráticos (véase Canovan 2005). Pero, aunque la democracia directa no puede ser el fundamento del gobierno de sociedades complejas, el populismo sostiene que debería serlo. Y lo hace mientras crea al pueblo por medio de elementos discursivos y estéticos que encuentran en las nuevas tecnologías digitales una herramienta de formidable potencia.

\section{Conclusión}

Este artículo ha propuesto una exploración de las bases afectivas del populismo, a partir de una caracterización del mismo como estilo político cuyos elementos performativos y estéticos poseen una especial importancia. Algo que la digitalización de la esfera pública -en el marco de la 
más amplia medialización de la sociedadno hace sino reforzar. En ese sentido, el trabajo ha prestado atención, sucesivamente, a los distintos elementos que conforman la dimensión emocional del estilo político populista y a la manera en que esa afectividad pueda haber encontrado nuevas formas de expresión en un espacio público que está siendo reconfigurado por las tecnologías digitales de la comunicación. En este caso, un fenómeno sirve para iluminar al otro; pero ambos se refuerzan también mutuamente. El populismo se ve así reforzado por la digitalización, que le proporciona nuevos instrumentos con los que dramatizar la crisis y "crear" el pueblo al que se dirige; la sentimentalización de la política se expresa a través del auge populista; la digitalización presenta rasgos marcadamente afectivos. Se sigue de aquí que la sentimentalidad populista debe entenderse por sí misma y en conexión con la digitalización. Respecto de lo primero, se ha presentado un análisis de los rasgos afectivos del populismo, que abarca desde el empleo del tribalismo moral a la función emocional del líder carismático, pasando por el rechazo del racionalismo como base para el orden social o los distintos elementos de un estilo político de clara vocación performativa. En cuanto a lo segundo, se han descrito los rasgos del proceso de digitalización que con más claridad sirven al empleo populista de las emociones: la posibilidad de establecer una relación directa entre liderazgo y seguidores, la rapidez con que se difunden noticias falsas o tenidas como "propias", la desintermediación y su condigno desprestigio de expertos y representantes, la producción de públicos afectivos y el creciente aislamiento cognitivo de los ciudadanos.

\section{Bibliografía}

Albertazzi, D. y McDonnell, D. (2008) "Introduction: The Sceptre and the Spectre", en D. Albertazzi y D. McDonnell (eds.), Twenty-First Century Populism. The Spectre of Western European Democracy, Houndmills, Palgrave-Macmillan, pp. 1-13.

Arias Maldonado, M. (2016) La democracia sentimental. Política y emociones en el siglo XXI, Barcelona, Página Indómita.

Arias Maldonado, M. (2017) "La digitalización de la conversación pública”, Revista de Estudios Políticos, n 173, Julio/ Septiembre, pp. 27-54.

Baumeister, R. F. y Leary, M. R. (1995) "The need to belong: Desire for interpersonal attachments as a fundamental human motivation". Psychological Bulletin, 117(3), pp. 497-529.

Canovan, M. (1981) Populism, Londres, Junction.

Canovan, M. (2005) The People, Cambridge, Polity.

Castells, M. (2008) Comunicación y poder, Madrid, Alianza.

Coleman, S. (2013) How voters feel, Cambridge, Cambridge University Press.

De la Torre, C. (2010) "Introduction: Power to the People? Populism, Insurrections, Democratization", en C. De la Torre (ed.), The Promise and Perils of Populism. Global Perspectives, Lexintong, University Press of Kentucky, pp. 1-28.

Deuze, M. (2012) Media Life, Malden, Polity.

Haidt, J. (2012) The righteous mind. Why good people are divided by politics and religion, Londres y Nueva York, Penguin.

Han, B.C. (2013) Im Schwarm. Ansichten des Digitalen, Berlín, Matthes \& Seitz.

Ionescu, G. y Gellner, E. (eds.) (1969) Populism, its Meanings and National 
Characteristics, Londres, Weidenfeld \& Nicolson.

Forgas, J. P. (2000) Feeling and thinking: the role of affect in social cognition, Cambridge, Cambridge University Press.

Freeden, M. (1998) "Is Nationalism a Distinct Ideology?", Political Studies, 46(4), pp. 748-765.

Gat, A., y Yakobson, A. (2013) Nations: The long history and deep roots of political ethnicity and nationalism, Cambridge University Press, Cambridge.

Greene, J. (2013) Moral Tribes. Emotion, reason, and the gap between us and them, Londres, Atlantic Books.

Hammack, P. y Pilecki, A. (2012) "Narrative as a Root Metaphor for Political Psychology", Political Psychology, 33(1), pp. 75-103.

Howard, P. and Hussain, M. (2013) Democracy's fourth wave? Digital media and the Arab Spring, New York, Oxford University Press.

Kahneman, D. (2003) "A perspective on judgement and choice: Mapping bounded rationality", American Psychologist, 58, pp. 697-720.

Kahneman, D. (2011) Thinking, fast and slow, Londres y Nueva York, Allen Lane.

Kolbert, E. (2017) "Why facts don't change our minds", The New Yorker, 27 febrero 2017.

Koselleck, R. (1978) "Volk, Nation, Nationalismus, Masse", en O. Brunner, W. Conze y R. Koselleck (eds.), Geschichtliche Grundbegriffe. Historisches Lexikon zur politisch-sozialen Sprache in Deutschland, vol. 7, Hamburgo, , Klett-Cotta, pp. 141-432.

Laclau, E. (2005) La razón populista, México DF, Fondo de Cultura Económica.

Lakoff, G. (2005) Don't think of an elephant! Know your values and frame the debate, White River Junction, Chelsea Green Publishing.

Lassalle, J. M. (2017) Contra el populismo: cartografía de un totalitarismo posmoderno, Barcelona, Debate.

Moffit, B. (2016) The Global Rise of Populism. Performance, Political Style, and Representation, Stanford, Stanford University Press.

Moffit, B. y Tormey, S. (2014) "Rethinking Populism: Politics Mediatisation and Political Style", Political Studies, 62, pp. 381-397.

Mouffe, C. (2000) Chantal Mouffe, The Democratic Paradox, Londres, Verso.

Mudde, C. (2004) "The populist Zeitgeist", Government \& Opposition, 39 (4), pp. 541- 563.

Müller, J-W. (2016) Was ist Populismus. Ein Essay, Berlín, Suhrkamp.

Neuman, W. R. (2016) The Digital Difference. Media Technology and the Theory of Communication Effectcs, Cambridge y Londres, Harvard University Press.

Ostiguy, P. (2009) "The High-Low Political Divide: Rethinking Populism and AntiPopulism", Political Concepts: Commitee on Concepts and Methods Working Paper Series, 35.

Paasonen, S., Hillis, K., Petit, M. (2015) "Introduction: Networks of Transmission: Intensity, Sensation, Value". In: K. Hillis et al. (eds.), Networked Affect, Cambridge and London, The Mit Press.

Panagia, D. (2009) The Political Life of Sensation, Durham, Duke University Press.

Papacharissi, Z. (2015) Affective Publics. Sentiment, Technology, and Politics, Oxford, Oxford University Press.

Pels, D. (2003) "Aesthetic Representation and Political Style: Re-balancing Identity and Difference in Media Democracy", en 
J. Corner y D. Pels (eds.), Media and the Restyling of Politics, Londres, Sage, pp. 41-66.

Reese, S., Routigliano, L., Hyun, K., Jeong, J. (2007) "Mapping the Blogosphere: Professional and Citizen-based Media in the Global News Arena", Journalism, 8(3), pp. 235-261.

Rivero, A., Zarzalejos, J., Del Palacio, J. eds. (2017) Geografía del populismo. Un viaje por el universo del populismo desde sus origenes hasta Trump, Madrid, Tecnos.

Sandvoss, C. (2013) "Towards an understanding of political enthusiasm as media fandom: Blogging, fan productivity and affect in American Politics", Participations. Journal of Audience \& Reception Studies, 10(1), pp. 252-296.

Stanley, B. (2008) "The Thin Ideology of Populism", Journal of Political Ideologies, 13(1), pp. 95-110.

Schechner, R. (2002) Performance studies: An introduction, New York, Routledge.

Sunstein, C. (2008) Republic.com 2.0, Princeton, Princeton University Press.

Sunstein, C. (2009): On Rumors: How Falsehoods Spread, Why We Believe Them, What Can Be Done, Nueva York, Farrar Strauss.

Taggart, P. (2000) Populism, Buckingham \& Philadelphia, Open University Press.

Thompson, MN. (2016) Enough Said: What's Gone Wrong With the Language of Politics, Londres, Bodley Head.
Thompson, S. y Hoggett, P. eds. (2012) Politics and the Emotions. The Affective Turn in Contemporary Political Studies, Londres, Continuum.

Vallespín, F. y Martínez-Bascuñán, M. (2017) Populismos, Madrid, Alianza.

Vallespín, F. (2012) La mentira os hará libres. Realidad y ficción en la democracia, Barcelona, Galaxia Gutenberg.

Van Kessel, S. (2015) Populist Parties in Europe. Agents of Discontent, Houndmills?, Palgrave Macmillan.

Villacañas, J. L. (2015) Populismo, Madrid, La Huerta Grande.

Werz, N. (2003) "Einleitung: Populismus und Populisten", en N. Werz (ed.), Populismus: Populisten in Übersee und Europa, Leske, Leske \& Budrich, pp. 7-14.

Westen, D. (2007) The Political Brain. The Role of Emotion in Deciding the Fate of a Nation, Nueva York, Public Affairs.

Weyland, K. (2001) "Clarifying a Contested Concept: Populism in the Study of Latin American Politics", Comparative Politics, 34(1), pp. 1-22.

Worsley, P. (1969) "The Concept of Populism", en G. Ionescu y E. Gellner (eds.), Populism, its Meanings and National Characteristics, Londres, , Weidenfeld \& Nicolson pp. 212-250.

Wu, T. (2012) The Master Switch. The Rise and Fall of Information Empires, Nueva York, Alfred A. Knopf. 